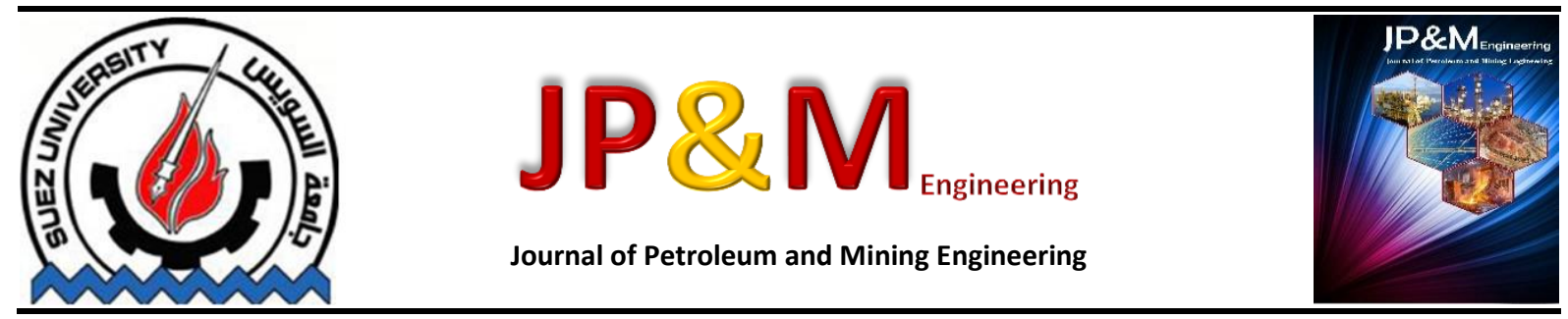

\title{
Understanding of Visco-Elastic Surfactant and Acid Stimulation Application
}

\author{
Ahmed A. Elgibaly ${ }^{a}$, Mohamed S. Farhat ${ }^{a}$, Hisham Nasr El Din ${ }^{b}$ and Wael A. F. Ahmed \\ ${ }^{a}$ Faculty of Petroleum \& Mining Engineering, Suez University, Suez, Egypt

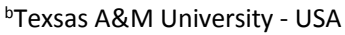 \\ *Corresponding author Tel.: +201224634515
}

\section{Keywords}

Surfactant; Visco-Elastic.

\begin{abstract}
Surfactants are divided into four main categories based on their ionic charge. The most common applications can be summarized as corrosion inhibitor, emulsifying and de-emulsifying agents, foaming agent and improver of solids carrying capacity. Visco-Elastic Surfactant (VES) is one of surfactant groups initially used as a friction reducer and to enhance the solids carrying capacity. In this paper many tests were performed on VES samples of newly produced product to study the work frame and the applicability of that product especially through three important factors 1) Viscosity build-up of the VES at different shear rates, 2) Study different concentrations behavior of the VES and its application especially on acid diversion, 3) Salt effect on the formed mixture of VES and its effect on the viscosity behavior, and finally 4) Temperature effect on the Visco-Elastic behavior was examined to define the work frame of that product (VES) application in the oil field in the acid diversion. VES product shows elasticity to stresses through the change in viscosity of the solution. Also, it was found that temperature affects negatively on the VES behavior, which limits the application of the VES in the high temperature reservoir, unless formation cooling action to be carried out before pumping the VES. On the other hand the salts have a positive effect on the VES behavior through increasing the viscosity buildup of the VES, which supports the application of VES in high saline formation water. The tested VES product shows good behavior as Visco-Elastic and could be used in limited temperature ranges, based on that result a case study was demonstrated in which it has been used as an acid diverter in carbonate reservoir. The well after the acid stimulation resulted in improving the well productivity and producing at $4100 \mathrm{BOPD}$ after stimulation.
\end{abstract}

\section{Introduction}

\section{Surfactants}

There are four categories of surfactants a) anionic surfactant, b) cationic surfactant, c) nonionic surfactant \& d) amphoteric surfactant. These four categories are classified based on its ionic group1. Surfactant is composed of two main parts, head; which is the carrier of the

ionic charge and the active part of the surfactant and tail; that represent the hydrocarbon part of the surfactant and differs from surfactant to other on the no. of alkyls on group2. Surfactants application usually depends on the ionic charge to support the purpose of application, for example in corrosion inhibitor, the cationic surfactant is used in cession inhibitor in order to be adsorbed on the tubular faces and cover it to form a film that helps preventing the acid attach to the tubular faces3.

Anionic surfactants are usually used as nonemulsifying agent or as friction reducer.

Nonionic surfactant is the widely used surfactant as it doesn't react with the other chemicals or with the formation's mineral, it is used in improve the flow back and reducing the surface tension, and finally the amphoteric surfactant, in which VES is the main member of this group, Amphoteric surfactant is a surfactant that has positive and negative charge at the same time and tends to be positive under certain $\mathrm{pH}$ rage4.

\section{Acid Diversion}

The success of matrix acidizing treatments depends on the placement of acid to remove nearwellbore formation damage efficiently. The acid should be placed so that all potentially productive 
intervals accept a sufficient quantity of the total acid volume. If significant permeability or formation damage variations are present in the interval to be treated, acid will enter the zones with the highest permeability or least formation damage, leaving little acid to treat what may be the most productive zones5. To achieve uniform damage removal, the original flow distribution across the treated interval needs to be altered to provide generally equal acid distribution. The methods used to alter this flow distribution are called diversion methods, since their purpose is to divert the flow of fluid from one portion of the interval being acidized to another6. The diversion method best suited for a particular situation depends on many factors, including the type of well completion, perforation density, the type of fluid that is produced or injected after the treatment, casing and cement sheath integrity, bottom hole temperature, and bottom hole pressure7. The best way to uniformly treat an interval is with a mechanical isolation device such as a straddle packer. This packer allows acid to be injected into small intervals, one by one, until the entire zone has been treated, however, this method is often not practical or possible without a packer; diverting agents must be used during stimulation to reduce flow into nonproductive or undamaged zones and redirect this flow to zones in greater need of damage removal8.

\section{Acid Diverters: Types and Uses}

Acid diversion alters the natural flow profile into a formation during injection, causing acid flow to be diverted from undamaged or high permeability intervals to damaged or lower permeability intervals9. The diversion methods used to alter the original flow profile may attempt to achieve complete shutoff of flow into specific intervals or to equalize flow across the entire interval being treated, regardless of permeability or damage severity10. The types of diverting methods fall into four general categories:

- Ball sealers

- Degradable particulate-diverting agents

- Viscous fluids

- Foam

\section{Experimental Work}

A set of experiments were done to emphasize on the VES physical properties to stand on the frame of application, temperature range, viscosity build up, concentrations \& range of acid strength.

\section{Materials and Methods}

The following apparatuses and equipments have been employed:-

- Brokfield viscometer to measure the viscosity of the fluid at different shear rates.

- Acid resistance magnetic Stirrer.

- Water bath.

- $\mathrm{pH}$ meter.
- $\mathrm{pH}$ caliber (Sulphonate solution with pH 7).

- Glass ware.

The following materials have been used:

- 37.1 \% Hydrochloric Acid ACS (American Chemistry Society).

- $\mathrm{CaCO}_{3} 93 \%$. (ACS).

- VES product with golen color, 0.99 Sp.Gr. \& amphoteric ionic charge.

\section{Study of Different VES Ratios in Acid Diversion}

Optimization is always the main target in any work, as optimization seeks the cost control and high performance. Each surfactant has the optimum concentration at which the maximum benefit can be achieved. Determine the optimum ratio of the VES is really important to minimize the cost of the treatment and to avoid any unexpected formation damage could be a result of that extra dosage. The test was run with $13 \% \mathrm{HCl}$ through applying different VES volume ratios $6,7,8 \& 10 \%$ by volume, the test results shows in fig (1) that with higher VES concentration, higher viscosity build up of the VES gel at the same shear rate is achieved. That result was a guide for more application of the VES based on the target or the purpose of the treatment either diversion or fluid loss control. As it is known in fluid loss control higher viscosity is required to have a complete blockage of the targeted interval. Also it shows the optimum application based on the formation permeability, as with higher permeable interval, higher viscosity is more

desirable than lower viscosity. VES with $400 \mathrm{cp}$ to $600 \mathrm{cp}$ is enough to divert the acid to another interval with low permeability, $6 \%$ to $7 \%$ by volume concentration of VES solution has the that range of viscosity which is enough in acid diversion application as shown in figure 1.

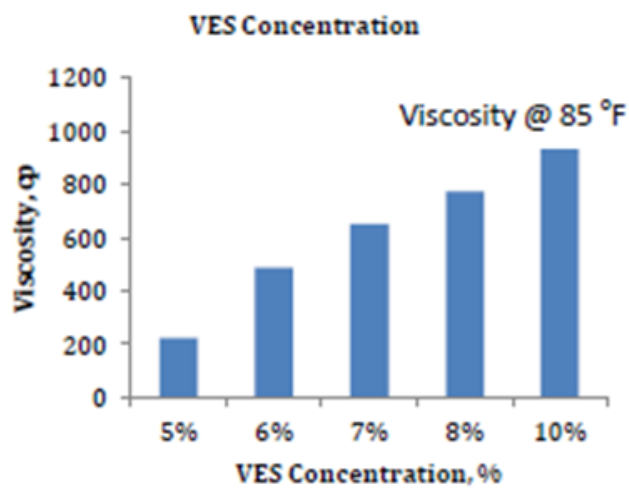

Figure 1 VES Concentration Effect.

\section{Temperature Effect on the Gelling Action}

Reservoir temperature has an important impact on the performance of any injected chemicals into the reservoir, as temperature acts as a reaction rate accelerator. In our study we are trying to understand the behavior of the VES under different temperature ranges to simulate the reservoir temperature effect. VES Solutions with different load concentrations 5, 6, $7,8 \& 10 \%$ of VES was examined to determine the limitations of VES application at different temperature 
ranges. In Fig (2) below shows that temperature has a negative impact on the VES gelling action behavior. At high temperature the VES loss its viscosity and break down to low viscosity solution. All curves in figure 2 show a peak value of viscosity at certain temperature, and then viscosity starts to decline with temperature increase which proves that temperature helps to a certain limit as a reaction rate accelerator to build up the viscosity of the VES solution then with higher temperature the viscosity starts to break down.

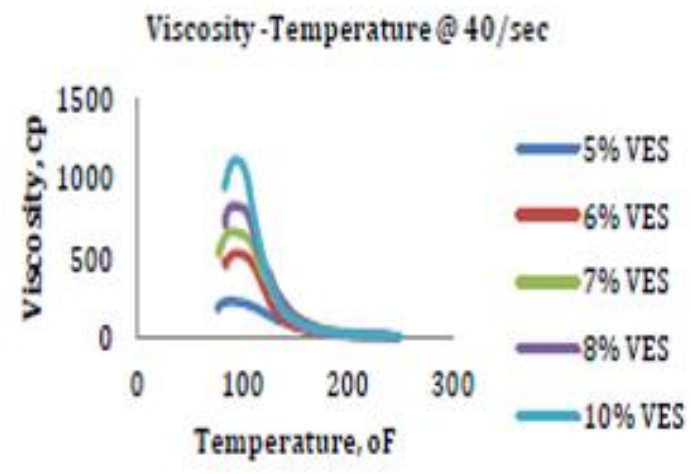

Figure 2 Temperature Effect on VES.

\section{Visco-Elastic Behavior at Different Shear Rates}

Visco-Elasticity is the ability of a gel to deform under stress and restore normal viscosity once the applied stress is removed. This feature is important in acid diversion mechanism as the pumped fluid exposure to different range of stresses through the formation; the pumping rate, tubing friction; drag force, formation permeability and friction inside the formations are aspects of the stress that gel exposed to. So to examine the Visco-Elastic capability of the selected VES is essential to understand the behavior of the VES within the formation. Different shear rates were applied on two different VES solutions 3\%\&4\% VES and then to observe the change of viscosity behavior at different shear rates. Moderate shear rate and very low shear rate were applied, to fully understand and assure the Visco-Elastic behavior of the subject surfactant VES over a wide range of shear rates. Figures (3) \& (4) below show the VES viscosity responses to moderate and very low shear rates respectively.

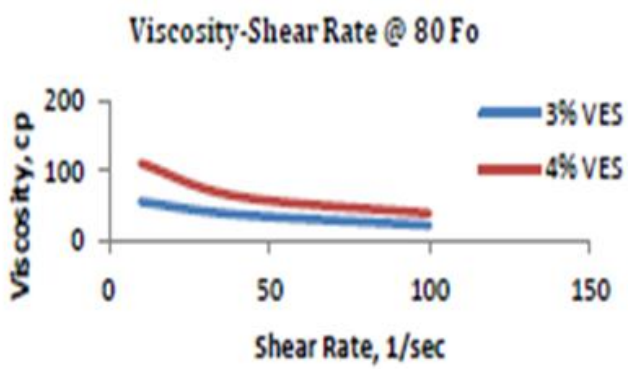

Figure 3 Visco-Elastic Behaviour of the VES.

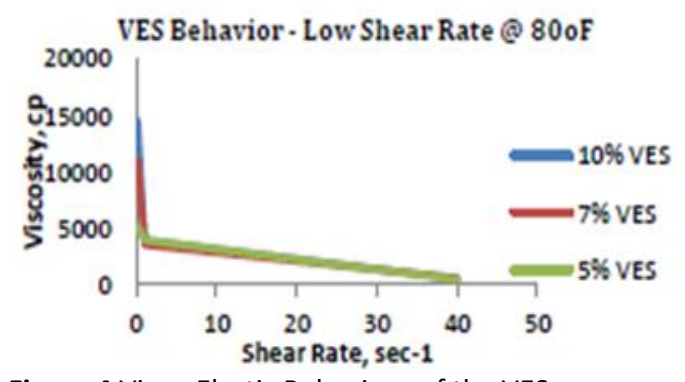

Figure 4 Visco-Elastic Behaviour of the VES.

\section{Effect of Salts Concentration on VES Behavior}

Formation water is full of salts such as $\mathrm{NaCl} \&$ $\mathrm{CaCl} 2$, once the VES solution is pumped to the formation it comes into contact with the formation water. Also, in acid diversion, the VES is carried by hydrochloric acid that reacts with the carbonate formations and release $\mathrm{CaCl} 2$ as a reaction result. So, examine different concentrations of salts of on the VES behavior at different temperatures is important to understand the VES performance within thereservoir. Figure 5 shows a viscosity build-up with higher salt consternations, that result in a positive effect of the salts on the VES performance as higher viscosity is required to support the diversion action of the VES. Also figure 6 shows the temperature effect on VES solutions mixed with different concentrations of $\mathrm{CaCl} 2$ salt. Temperature has a negative effect on the gel viscosity of the VES mixed with salts but the viscosity decline is not sharp and keeps the viscosity of the VES solution in the application range.

\section{Salts Effect on Viscosity Response}

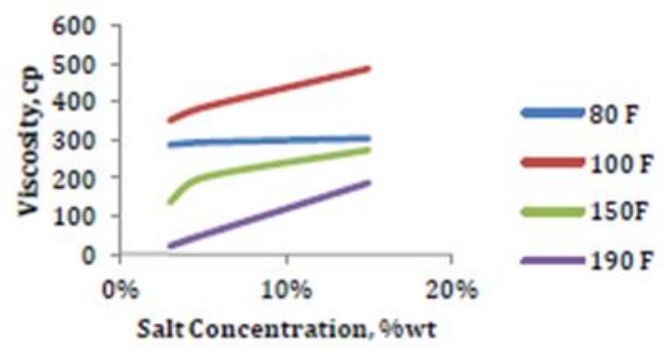

Figure 5 Viscosity Response with Salts Concentration.

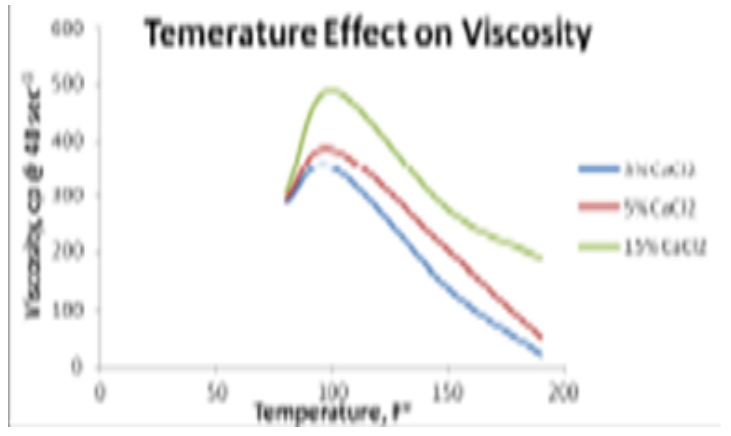

Figure 6 Temperature Effect onVES at Different Salts Concentration.

\section{Case Study}

An oil well lies in the southern area of West Qurna field, Basra, Iraq, recently drilled into Mishrif carbonate formation at $2535 \mathrm{~m}$ with a perforated interval of $100 \mathrm{~m}$. The reservoir average temperature 
is $177 \mathrm{oF}$, and the oil is $32 \mathrm{o} \mathrm{API}$, no evidence for $\mathrm{H} 2 \mathrm{~S}$. The pay zone is of three intervals with different permeability and reservoir pressure as shown in figure 7, The well after completion was flowed back, showing very low productivity index, with a total daily production of 320 BOPD, the formation damage was attributed to the mud loss during the drilling of the pay zone, LCM (loss Circulating Material) was used to stop losses to the formation which includes medium calcium carbonate materials.

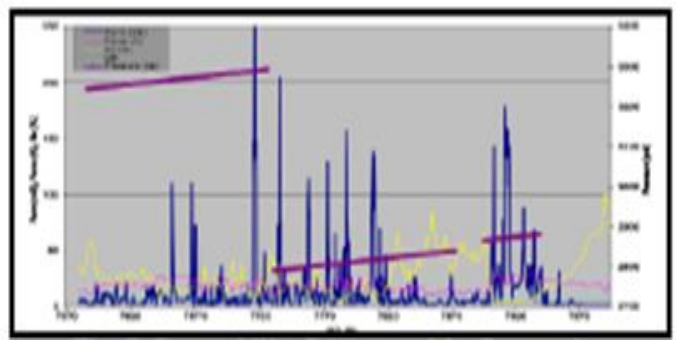

Figure 7 Permeability Pressure of the Reservoir.

The decision was made to acid stimulate the pay zone to enhance the productivity and to create new channels to overcome the drilling and workover fluid damage. The perforated interval is $328 \mathrm{ft}$, and has permeability and pressure heterogeneity, so diversion in this case was important to have fair acid distribution. VES with $15 \% \mathrm{HCl}$ acid diversion technique was selected due to its minimal residual damage compared to other chemical techniques. Table 1 shows the pumping schedule of the $15 \% \mathrm{HCl}$ Table 1 Acid Treatment Pump Schedule. acid and the VES acid diversion in stages, where figure 8 shows the pumping pressure changes due to the change in the pumped fluid and the effect of the gelling action. Change in pressure reflects the response of the formation resistance to the VES solution, pressure build-up was a result of the VES gelling action as the formed gels plugged the high permeable intervals and divert the acid the rest of the interval. The well then flowed back through coiled tubing nitrogen lifting, the well started to flow back and cleaning itself, once the spent acid out of the formation, the production has been diverted to the well test separator, the flowing period test showed a production of 2400 bbls/day @ 320psi WHP and 46" chock size.

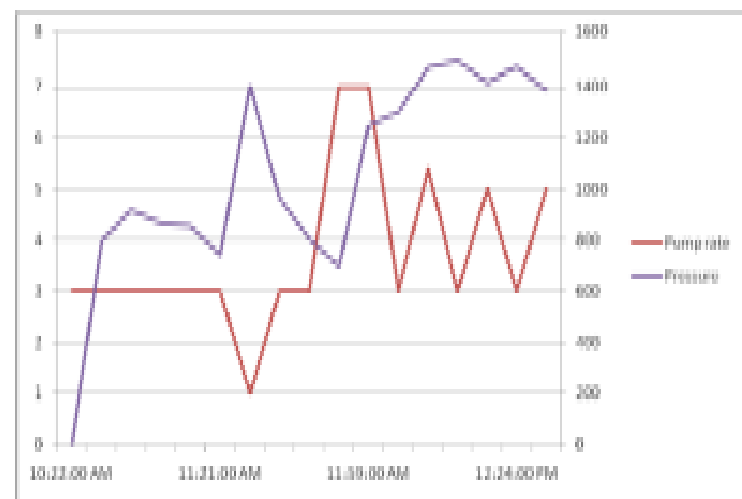

Figure 8 Pressue Pumping Curve.

\begin{tabular}{|c|c|c|c|c|c|c|c|c|c|c|}
\hline \multicolumn{11}{|c|}{ P.mping Procedure tor OIl Production Well } \\
\hline \multicolumn{11}{|c|}{ Ballead of $15 \%$ HCI With VES DGorter } \\
\hline & ind & m & 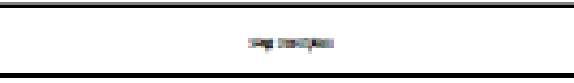 & and & \multicolumn{2}{|c|}{ 筮 } & 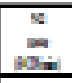 & and & 5 & $=$ \\
\hline & & & 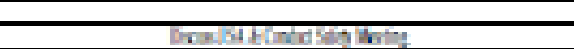 & $=$ & $=$ & 国 & & ine & $\frac{1}{1+m}$ & एi丶 \\
\hline I & & & The & & & & & & Linin & IISTin \\
\hline 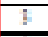 & 7 & Thullets & 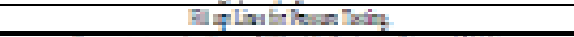 & $\mathrm{x}$ & & & & III & $4=$ & $\operatorname{LA}=$ \\
\hline I & $\pi$ & Finen & 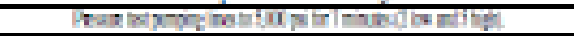 & 5 & & & & 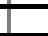 & $\operatorname{Tin}$ & Itsm \\
\hline 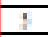 & & & 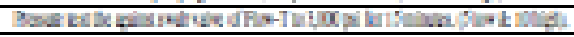 & & & & & & Din & Al:in \\
\hline E & & Mons & 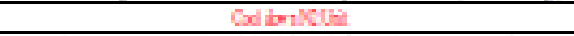 & & In & Bin & & & B= & 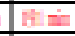 \\
\hline$\pi$ & II & Theriente & 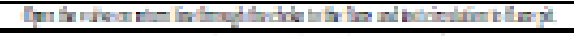 & iil & & & & III & $\ln$ & 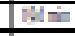 \\
\hline II & & & 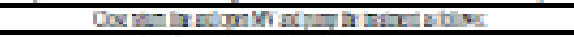 & & & & & & $\mathrm{Bn}$ & min \\
\hline 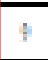 & II & Theserte- & 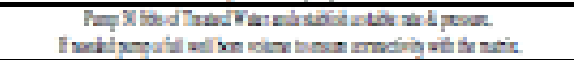 & يقية & & & & 10 & int & $D=$ \\
\hline Tin & 볼 & BDHHI & Fin & Lete & & & & 姐 & atran & ت7s \\
\hline III & II & Deaventen & Fynesing & $4 x$ & & & & 果 & 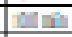 & Prin \\
\hline II & 대 & BHALC & $P=\ln B D$ & Les & & & & iin & 1810 & $\mathrm{sin}=$ \\
\hline If & II & 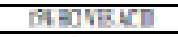 & 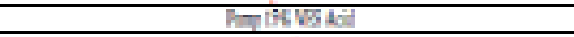 & 19 & & & & Bin & min & itini \\
\hline 14 & 료 & BAHIL & 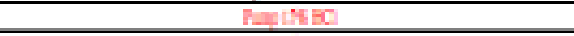 & 53 & & & & W & Fin & $8 \mathrm{sin}^{2}$ \\
\hline if & I & 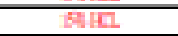 & Pralfing & Lit: & & & & 国闻 & In & $y=$ \\
\hline it: & 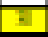 & 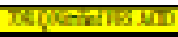 & 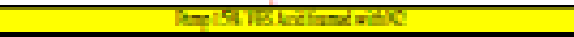 & $\mathbb{E}$ & Fin & in & $I=1$ & (10) & tint & 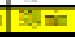 \\
\hline$\pi$ & II & PBHIII & FMLHAD & 5 & & & & 四 & Tin & 新再 \\
\hline II & $\mathbb{1}$ & BमाH & 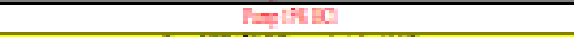 & Litit & & & & m & $2 i=\sin$ & Penti \\
\hline Nit: & tis & 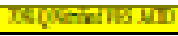 & 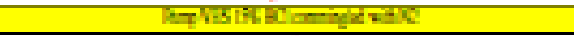 & $\pi$ & +6 & sii & $\mathrm{N}=$ & LF & in & $5 \pi$ \\
\hline$\pi$ & 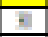 & BSHCL & FunLAR: & Da & & & & 110 & $7=$ & Dn \\
\hline a & \pm & BAHI & 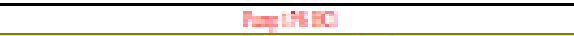 & Lit! & & & & nin & $2=$ & EH \\
\hline I & 3 & MtEIENTI & 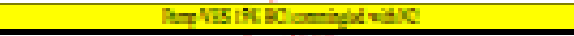 & 5 & 프 & 18 & जा & 娄 & $x=i$ & On \\
\hline Ts & \pm & TBIHL & 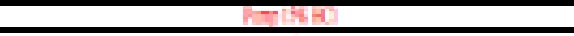 & in & & & & Di. & Ding & Din min \\
\hline I & I & [DIHL & Fanderie & In: & & & & Din & DIn & sin init \\
\hline 3 & $\mathbb{I}$ & Therelest & 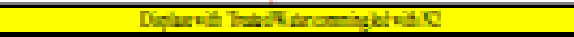 & in & 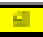 & Fis & $\mathrm{N}=$ & 西 & 2I=in & DOF \\
\hline T & $=$ & 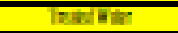 & 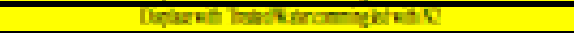 & Lin & EI & ini & Int & Wiा & 프 & Dit \\
\hline 五 & 要 & Thane & 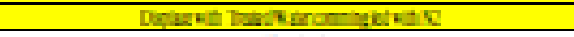 & 는. & $B$ & 11.5 & IE & 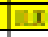 & 5in-1n & 본 \\
\hline I & & & 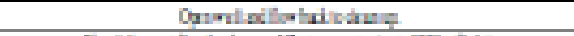 & & & & & & Fitming & 贾业 \\
\hline 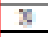 & & & 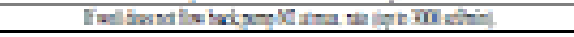 & & & & & & Bin & m nim \\
\hline I & & & 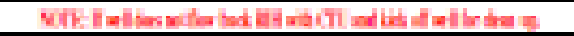 & & & & & & & 호뇨 \\
\hline & ET & & Thut & set & 240 & Wa & & & & Pln \\
\hline
\end{tabular}




\section{Conclusions}

- The tested VES product is valid for oil field application at limited temperature range.

- Concentration of the VES will depend on the purpose of the application. Higher concentrations of VES can build-up a solution with a viscosity of $1000 \mathrm{cp}$ which can be used as a fluid loss control treatment.

- Temperature affects negatively on the VES gelling action.

- Salts support the viscosity build-up of the VES solution.

- VES can successfully divert acid and allow fair acid distribution that will support enhancing the wellproductivity.

\section{Acknowledgements}

The authors wish to acknowledge the Suez University for granting permission to present and publish this paper. The authors would like to thank the department of the Petroleum Engineering.

\section{References}

[1] Tadros. T.T, : Applied Surfactant: Principles and Applications, PP 19-26, First Edition, Wiley-VCH- USA, 2006.

[2] N. M. Os van, J. R. Hauk, L. A. M. Rupert. : "Physicchemical Properties of Selected Anionic, Cationic and Nonionic Surfactants", Elsevier, Amsterdam, 1993.

[3] E. H. Lucasssen- Reynders: "Anionic Surfactants Physical Chemistry of Surfactant Action", Marcel Dekker, New York, 1981.

[4] Tadros. T.T,: “Applied Surfactants: Principles and Applications" PP 113- 125 Hoboken, Wiley-VCH, USA, 2006.

[5] S. S. Ashrawi. "Hot water, surfactant, and polymer flooding process for heavy oil". Patent: US 5083612, 1992.

[6] N.H. Ginest,: "Field Evaluation of Acid simulation Diverter Materials and Placement Methods in Arab-D Injection Wells with Open hole Completion", paper SPE 25412 presented at the 1993 Middle East Oil Technical Conference and Exhibition, Bahrain, 3-6, April 1993.

[7] S.J. Black, and J.L Rike,: "The Role of the Consultant in Meeting the Formation Damage Challenge," paper SPE 5700 , presented at the SPE Symposium on Formation Damage Control, Houston, Texas, USA (January 29-30, 1976).

[8] A. Joseph, E Leon, and M. Scott, SPE,: "Characterization and Evaluation of Formation Damage During Water Flooding of A High Clay Content Reservoir" Paper SPE 16234 MS, Reservoir Engineering, Nov. 1988.

[9] J. MaGee, M.A., and R. .Pongratz,: "Method for Effective Fluid Diversion when Performing a Matrix Acid Stimulation in Carbonate Formations," paper SPE 37736 presented at the 1997 Middle East Oil Show, Bahrain, 15-18 March 1997.
[10] A.Toseef and D.J. Beaman, SPE, Halliburton, and P. Birou, Total E\&P.: "Viscoelastic Surfactant Diversion: An Effective Way to Acidize Low- Temperature Wells" Paper SPE 136574-MS, Abu Dhabi International Petroleum Exhibition and Conference, 1-4 November 2010, Abu Dhabi, UAE. 